\title{
The short-term and long-term outcomes of indocyanine green tracer-guided laparoscopic radical gastrectomy in patients with gastric cancer
}

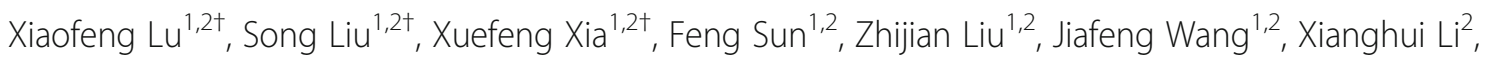
Zhengyang Yang ${ }^{3}$, Xing Kang ${ }^{1,2}$, Shichao $\mathrm{Ai}^{1,2^{*}}$ (i) and Wenxian Guan ${ }^{1,2^{*}}$

\begin{abstract}
Background: The safety and efficacy of indocyanine green (ICG) imaging navigational laparoscopic gastrectomy remain controversial. This study is to evaluate the short-term and long-term outcomes of ICG-guided laparoscopic radial gastrectomy in patients with gastric cancer.

Methods: Consecutive patients with definitive diagnosis of gastric cancer that underwent laparoscopic radical gastrectomy were collected retrospectively. Propensity score matching (PSM) at 1:1 ratio was performed to compare the outcomes of two groups.

Results: A total of 122 qualified patients were divided into ICG group $(n=34)$ and non-ICG group $(n=88)$. PSM yielded 28 patients with comparable baseline characteristics into each group. The number of retrieved lymph node in ICG group was significantly higher than that in non-ICG group $(P=0.0196)$. There was no statistical difference of perioperative, short-term, and long-term complications between the two groups.
\end{abstract}

Conclusion: ICG-guided laparoscopic radical gastrectomy is safe and effective, and ICG-navigated lymphadenectomy improves the number of retrieved lymph nodes for patients with gastric cancer.

Keywords: Gastric cancer, Laparoscopic gastrectomy, Indocyanine green, Short-term outcomes, Long-term outcomes

\section{Introduction}

Radical laparoscopic gastrectomy (LG) has been widely used in the management of gastric cancer (GC) for its minimal invasiveness and early postoperative recovery [1-3]. As one of the key and most difficult step in the radical operation, lymphadenectomy has been confirmed to be closely associated with the accuracy of pathological

\footnotetext{
* Correspondence: medasc@smail.nju.edu.cn; medquanwenxian@163.com ${ }^{+}$Xiaofeng Lu, Song Liu, and Xuefeng Xia contributed equally to this work and share the first authorship.

'Department of General Surgery, Drum Tower Medical College of Nanjing Medical University, 321 Zhongshan Road, Nanjing 210008, Jiangsu, China Full list of author information is available at the end of the article
}

staging and long-term survival $[4,5]$. Traditionally, the identification and dissection of lymph node is largely relied on the surgeon's individual experience. It remains as a challenge to identify lymph nodes from hypertrophic adipose tissue and complex architecture of gastric lymphatics without increasing the risk of surgery and the incidence of postoperative complications. Therefore, improving the intraoperative visuality of lymph nodes stands as an urgent clinical issue to be resolved.

In recent years, near-infrared (NIR) imaging with indocyanine green (ICG) has been developed for the visualization of sentinel lymph nodes and real-time

(c) The Author(s). 2021 Open Access This article is licensed under a Creative Commons Attribution 4.0 International License, which permits use, sharing, adaptation, distribution and reproduction in any medium or format, as long as you give appropriate credit to the original author(s) and the source, provide a link to the Creative Commons licence, and indicate if changes were made. The images or other third party material in this article are included in the article's Creative Commons licence, unless indicated otherwise in a credit line to the material. If material is not included in the article's Creative Commons licence and your intended use is not permitted by statutory regulation or exceeds the permitted use, you will need to obtain permission directly from the copyright holder. To view a copy of this licence, visit http://creativecommons.org/licenses/by/4.0/ The Creative Commons Public Domain Dedication waiver (http://creativecommons.org/publicdomain/zero/1.0/) applies to the data made available in this article, unless otherwise stated in a credit line to the data. 
guidance of lymph nodes dissection in various cancers [6-9]. Due to the fine tissue penetration of signal, ICG-mediated NIR fluorescent imaging has become a promising technique in navigational laparoscopic surgery $[10,11]$.

The application of ICG in gastrectomy for gastric cancer originates two decades ago. It was initially used in sentinel lymph node navigation and anastomotic blood flow visualization [10, 12-15]. Recent studies begin to investigate the safety and effectiveness of ICG navigation in lymphadenectomy during laparoscopic radical gastrectomy [16-21]. However, there lack studies that report the long-term outcome in patients receiving ICG-guided gastrectomy. Current study is dedicated to evaluate both short-term and long-term outcomes of ICG-navigated lymphadenectomy in patients with gastric cancer.

\section{Methods}

\section{Patients}

Consecutive patients that underwent radical laparoscopic gastrectomy between July 2015 and October 2019 at Nanjing Drum Tower Hospital, the Affiliated Hospital of Nanjing University Medical School were retrospectively collected. Inclusion criteria were as follows: (1) preoperative pathology of endoscopic biopsy was gastric adenocarcinoma, (2) absence of distant metastasis, and (3) the American Society of Anesthesiology (ASA) physical status score $\leq 3$. Exclusion criteria were (1) postoperative pathology was not primary gastric adenocarcinoma, (2) conversion to open gastrectomy, (3) clinical or pathological data was incomplete, and (4) lost to follow-up.

All qualified cases were divided into two groups according to the use of ICG during operation. All cases were then matched by Propensity Score Matching at 1:1 ratio to yield comparable baseline characteristics between two groups.

\section{Data extraction}

The following data were extracted from clinical database: patient characteristics (age, gender, BMI and ASA grade), preoperative data (clinical $\mathrm{T}$ and $\mathrm{N}$ stages, preoperative histological type according to endoscopic biopsy), intraoperative events (operation time, surgical approach and blood loss), and postoperative pathological data and outcomes.

Short-term outcome was defined as outcome within 30 days after surgery, including short-term complications, postoperative hospital stays, reoperation due to complications, adverse effect of ICG injection, morbidity of preoperative endoscopy, and postoperative mortality. The postoperative complication was evaluated using Clavien-Dindo classification [22].
Long-term outcome was defined as outcome collected at each out-patient visit after discharge, including longterm complications (e.g., abdominal discomfort and anastomosis stricture), readmission or reoperation due to long-term complications, recurrence, and death during follow-up period.

\section{Administration of ICG}

Each patient in ICG group received endoscopic ICG (Dandong Yichuang Pharmaceutical Co., China) injection intraoperatively. The ICG powder was diluted to $2.5 \mathrm{mg} / \mathrm{ml}$ and the prepared solution $(0.5 \mathrm{ml}$ at a time) was injected at proximal and distal submucosa of the tumor (Fig. 1).

\section{Laparoscopic equipment}

The Endoscopic Fluorescence Imaging System (PINPOINT, NOVADAQ, Mississauga, ON, Canada) was used to obtain NIR fluorescent images during operation. The system enables to provide high-definition white light, NIR irradiation, and back-filtration tuned for ICG specifically. The system also allows simultaneous display of multiple images including standard high definition white light imaging, NIR fluorescence imaging, and SPY imaging (Fig. 2). Surgeons are able to switch the imaging mode with a finger click.

\section{Surgical approach}

The indication for radical distal gastrectomy is T2-4 or $\mathrm{N} 1-3$, and the proximal resection margin $\geq 3 \mathrm{~cm}$ (localized tumor) or $\geq 5 \mathrm{~cm}$ (invasive tumor). The indication for radical total gastrectomy is $\mathrm{T} 2-4$ or N1-3 while the proximal resection margin cannot meet the requirement of distal gastrectomy. The indications for radical proximal gastrectomy are T1N0, upper stomach tumor, and more than half of the stomach can be retained. The gastrointestinal reconstruction for distal and total gastrectomy is Roux-en-Y reconstruction, and the reconstruction of proximal gastrectomy is double tunnel reconstruction [23]. All cases underwent D2 lymphadenectomy.

The lymph node sorting method was according to Japanese classification [24]. The number of retrieved lymph node is based on postoperative pathology report. Positive lymph node is defined as definitive existence of lymph nodes (not fibrous connective tissue) in the sorted lymph node-like tissues.

\section{Statistical analysis}

All data were analyzed with SPSS version 19.0 (SPSS Inc., Chicago, IL, USA). PSM analysis was conducted using a logistic regression model with the following covariates: age, gender, ASA grade, BMI, tumor location, clinical stage, and preoperative histological type. We adopted a caliper width of 0.02 for the pooled standard deviation of the logit for calculating the propensity score 


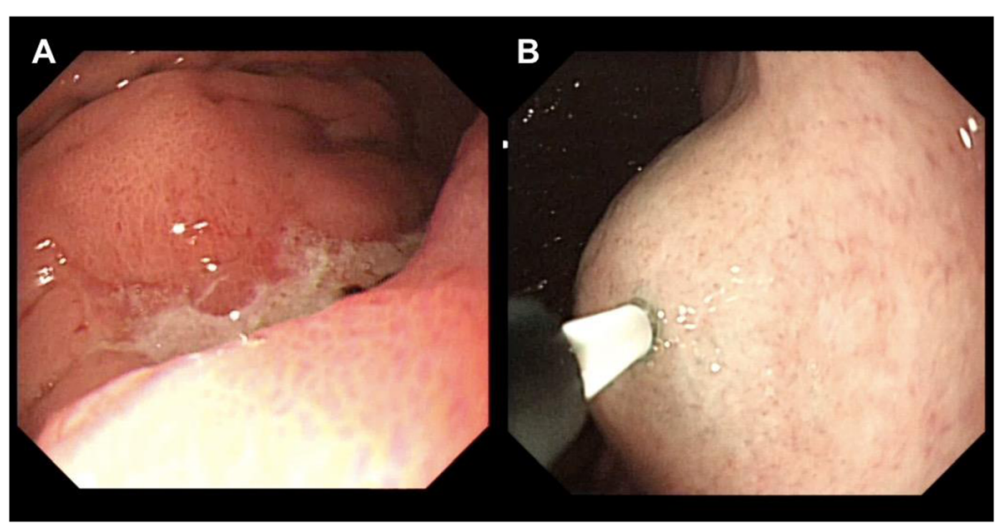

Fig. 1 Intraoperative ICG injection. Endoscopic view. A Before injection. B After injection

for PSM. All continuous variables were presented as mean \pm standard deviation (SD) and were calculated using Student's $t$ test or Mann-Whitney $U$ test. All categorical variables were presented as frequency and percentage and were calculated using chi-square test or Fisher's exact test. Statistical significance was considered when $p$-value is less than 0.05 .

\section{Ethics}

This study was approved by the Ethics Committee of Nanjing Drum Tower Hospital, Medial School of Nanjing University.

\section{Results}

Baseline characteristics

As shown in Fig. 3, a total of 139 consecutive cases underwent radical laparoscopic gastrectomy. Seventeen cases were excluded due to conversion to open gastrectomy (1 case), incomplete clinical or pathological data (2 cases), and lost to follow-up (14 cases). The remaining 122 cases were assigned into ICG group $(n=34)$ and non-ICG group $(n=88)$. Subsequent PSM yielded 28 cases in each group. Table 1 demonstrates that there was no statistical difference of baseline characteristics between ICG group and non-ICG group.

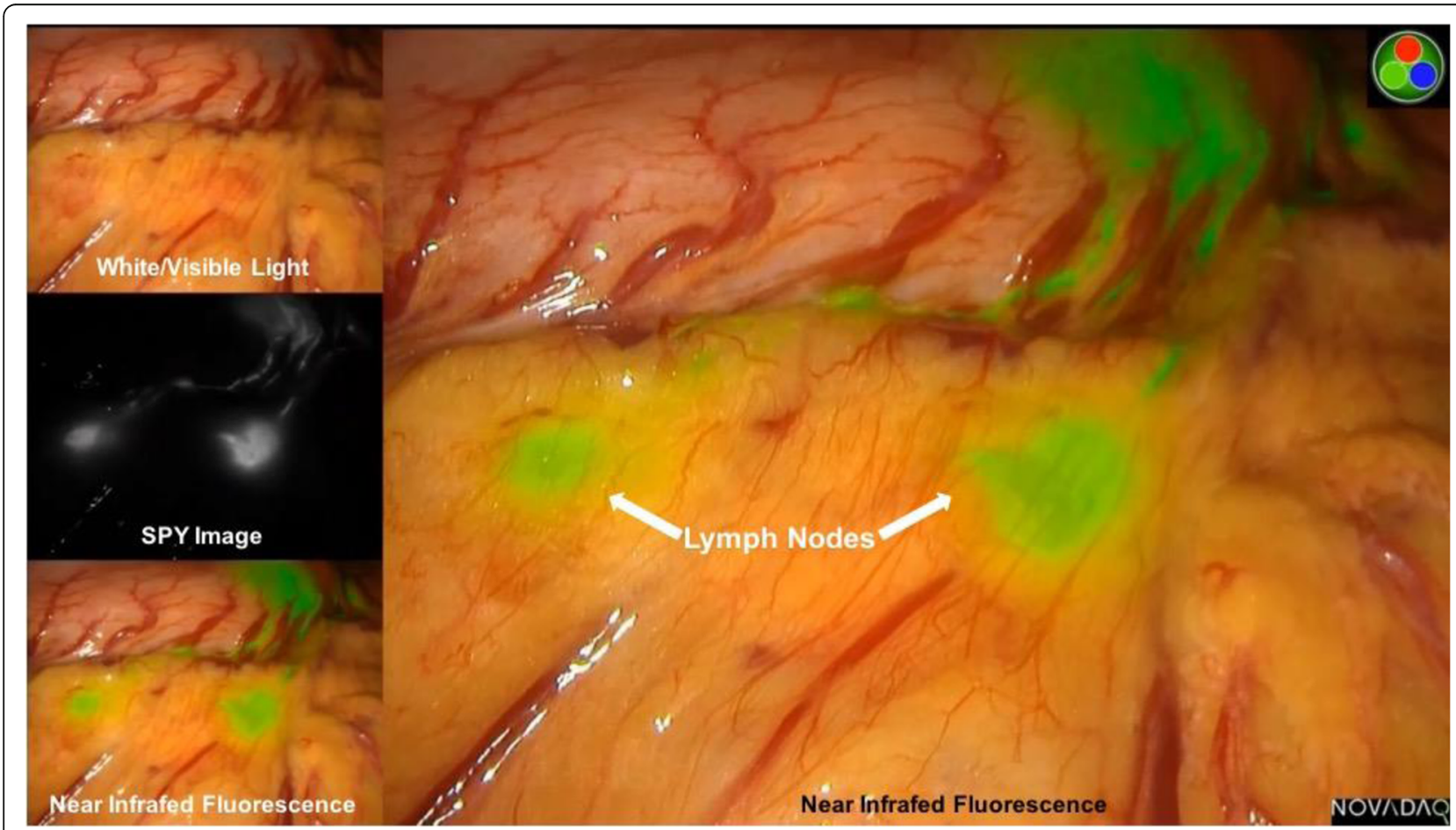

Fig. 2 ICG tracer-guided laparoscopic radical gastrectomy. Laparoscopic view 


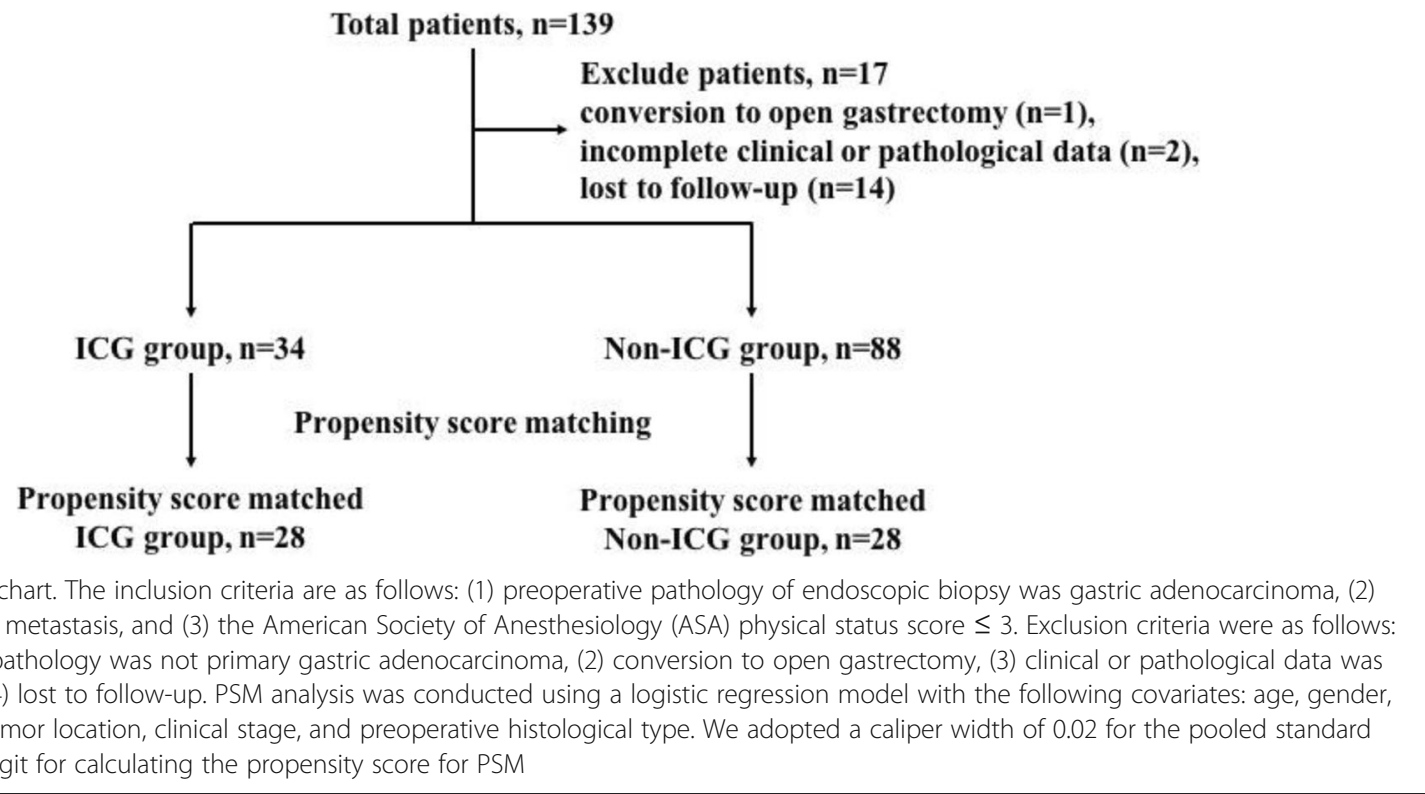

Table 1 Demographics and clinical characteristics between the ICG and non-ICG groups

\begin{tabular}{|c|c|c|c|}
\hline & ICG $(n=28)$ & Non-ICG $(n=28)$ & $P$ value \\
\hline Age (yrs.) & $57.96 \pm 12.66$ & $59.17 \pm 9.17$ & 0.6874 \\
\hline Gender (male, \%) & 19 (67.86\%) & $20(71.43 \%)$ & 0.7713 \\
\hline ASA-PS & & & $>0.9999$ \\
\hline$\|$ & $13(46.43 \%)$ & $13(46.43 \%)$ & - \\
\hline III & 15 (53.57\%) & $15(53.57 \%)$ & - \\
\hline BMI $\left(\mathrm{kg} / \mathrm{m}^{2}\right)$ & $22.25 \pm 2.32$ & $22.86 \pm 2.73$ & 0.3716 \\
\hline Tumor location & & & 0.2049 \\
\hline Upper third & $7(25.00 \%)$ & $10(35.71 \%)$ & - \\
\hline Middle third & 11 (39.29\%) & $5(17.86 \%)$ & - \\
\hline Lower third & $10(35.71 \%)$ & $13(46.43 \%)$ & - \\
\hline cT stage & & & 0.7744 \\
\hline CT1 & 17 (60.72\%) & 19 (67.86\%) & - \\
\hline $\mathrm{CT} 2$ & $8(28.57 \%)$ & $5(17.86 \%)$ & - \\
\hline CT3 & $3(10.71 \%)$ & $3(10.71 \%)$ & - \\
\hline CT4 & 0 & $1(3.57 \%)$ & - \\
\hline cN stage & & & $>0.9999$ \\
\hline CNO & $20(71.43 \%)$ & $20(71.43 \%)$ & - \\
\hline $\mathrm{cN}+$ & $8(28.57 \%)$ & $8(28.57 \%)$ & - \\
\hline Clinical stage & & & 0.6862 \\
\hline$|+| \mid$ & 25 (89.29\%) & $24(85.71 \%)$ & - \\
\hline III+IV & $3(10.71 \%)$ & $4(14.29 \%)$ & - \\
\hline Histological type & & & 0.5920 \\
\hline Well/Moderate & $14(50.00 \%)$ & $12(42.86 \%)$ & - \\
\hline Poor/Undifferentiated & $14(50.00 \%)$ & $16(57.14 \%)$ & - \\
\hline
\end{tabular}

TNM staging was based on the Japanese Classification of Gastric Carcinoma, 3rd English version

ASA-PS The American Society of Anesthesiology Physical Status Classification

\section{Short-term outcome}

Table 2 exhibits the perioperative outcomes between two groups. No significant difference was observed in operation time, blood loss, pT, pN, pStage, histological type, and postoperative hospital stay. The number of retrieved lymph node in ICG group was significantly higher than that in the non-ICG group $(P=0.0196)$. No endoscopy-related complication occurred, and no adverse effect of ICG injection was observed.

As shown in Table 3, there were 7 cases of complications in ICG group, including 2 fever, 1 intra-abdominal infection, 1 diarrhea, 1 gastroparesis, 1 bowel obstruction, and 1 anastomosis leakage. In the non-ICG group, there were 12 cases including 2 fever, 2 intra-abdominal infections, 1 diarrhea, 6 gastropareses, and 1 bowel obstruction. The incidence of short-term complication was $25.00 \%$ and $39.29 \%$ in the ICG and non-ICG groups, respectively $(P=0.1582)$. Subgroup analysis of mild (grades I and II) or major (grades III and IV) complications also demonstrated similar incidence between groups.

\section{Long-term outcome}

The mean duration of follow-up period in ICG and nonICG group was 21.25 and 26.29 months, respectively (Table 4). The incidence of long-term complication was similar between the two groups. In the ICG group, there were 5 cases of long-term complications including 2 abdominal discomfort, 1 anastomosis stricture, 1 bile reflux, and 1 anastomosis inflammation. In the non-ICG group, there were 3 cases including 1 abdominal discomfort, 1 gastrointestinal bleeding, and 1 bile reflux. The readmission rate was also similar between groups $(10.71 \%$ vs $3.57 \%, p=0.6110)$. In the ICG group, there 
Table 2 Perioperative outcomes between the ICG and non-ICG groups

\begin{tabular}{|c|c|c|c|}
\hline & ICG group $(n=28)$ & Non-group $(n=28)$ & $P$ value \\
\hline Operation time (min) & $260.18 \pm 46.7$ & $277.86 \pm 69.15$ & 0.2672 \\
\hline Blood loss (ml) & $144.64 \pm 83.15$ & $167.5 \pm 141.23$ & 0.4637 \\
\hline Type of resection & & & 0.2356 \\
\hline Proximal gastrectomy & $3(10.71 \%)$ & $6(21.43 \%)$ & - \\
\hline Distal gastrectomy & $10(35.71 \%)$ & $13(46.43 \%)$ & - \\
\hline Total gastrectomy & 15 (53.58\%) & $9(32.14 \%)$ & - \\
\hline Histological type & & & $>0.9999$ \\
\hline Well/Moderately & 11 (39.29\%) & $11(39.29 \%)$ & - \\
\hline Poor/Undifferentiated & 17 (60.71\%) & $17(60.71 \%)$ & - \\
\hline pT stage & & & 0.1418 \\
\hline pT1 & 22 (78.57\%) & $16(57.14 \%)$ & - \\
\hline pT2 & $4(14.29 \%)$ & $4(14.29 \%)$ & - \\
\hline pT3 & $1(3.57 \%)$ & 7 (25.00\%) & - \\
\hline pT4 & $1(3.57 \%)$ & $1(3.57 \%)$ & - \\
\hline pN stage & & & 0.0998 \\
\hline pNO & $23(82.15 \%)$ & $16(57.14 \%)$ & - \\
\hline $\mathrm{pN} 1$ & $1(3.57 \%)$ & $5(17.86 \%)$ & - \\
\hline pN2 & $2(7.14 \%)$ & $6(21.43 \%)$ & - \\
\hline pN3 & $2(7.14 \%)$ & $1(3.57 \%)$ & - \\
\hline pSt stage & & & 0.4688 \\
\hline$|+| \mid$ & 25 (89.29\%) & $22(78.57 \%)$ & - \\
\hline III+IV & $3(10.71 \%)$ & $6(21.43 \%)$ & - \\
\hline Number of retrieved LN (number) & $27.50 \pm 10.60$ & $21.79 \pm 6.73$ & 0.0196 \\
\hline Postoperative hospital stay (days) & $13.46 \pm 8.92$ & $15.71 \pm 9.15$ & 0.3556 \\
\hline Complication of intraoperative endoscopy & 0 & - & - \\
\hline Prevalence of adverse effects of ICG injection & 0 & - & - \\
\hline Postoperative mortality & 0 & 0 & $>0.9999$ \\
\hline
\end{tabular}

Table 3 Short-term complications between the ICG and nonICG groups

\begin{tabular}{llll}
\hline & ICG $(\boldsymbol{n}=\mathbf{2 8})$ & Non-ICG $(\boldsymbol{n = 2 8 )}$ & $\boldsymbol{P}$ value \\
\hline Overall $(n, \%)^{\mathrm{a}}$ & $7(25.00 \%)$ & $12(39.29 \%)$ & 0.1582 \\
Grade I or II $(\mathrm{n}, \%)^{\mathrm{a}}$ & $4(14.29 \%)$ & $5(17.86 \%)$ & $>0.9999$ \\
Fever & $2(7.14 \%)$ & $2(7.14 \%)$ & - \\
Intra-abdominal infection & $1(3.57 \%)$ & $2(7.14 \%)$ & - \\
Diarrhea & $1(3.57 \%)$ & $1(3.57 \%)$ & - \\
Grade III or IV ( $n, \%)^{a}$ & $3(10.71 \%)$ & $7(25.00 \%)$ & 0.2955 \\
Gastroparesis & $1(3.57 \%)$ & $6(21.43 \%)$ & - \\
Bowel obstruction & $1(3.57 \%)$ & $1(3.57 \%)$ & - \\
Anastomosis leakage & $1(3.57 \%)$ & 0 & - \\
\hline
\end{tabular}

Table 4 Long-term outcome between patients in the ICG group and non-ICG group

\begin{tabular}{llll}
\hline & ICG $(\boldsymbol{n}=\mathbf{2 8})$ & Non-ICG $(\boldsymbol{n}=\mathbf{2 8})$ & $\boldsymbol{P}$ value \\
\hline Duration of follow-up $(\mathrm{m})$ & $21.25 \pm 12.01$ & $26.29 \pm 14.51$ & 0.1625 \\
Overall complications $(n, \%)$ & $5(17.86 \%)$ & $3(10.71 \%)$ & 0.7049 \\
Abdominal discomfort & $2(7.14 \%)$ & $1(3.57 \%)$ & - \\
Anastomosis stricture & $1(3.57 \%)$ & 0 & - \\
Gastrointestinal bleeding & 0 & $1(3.57 \%)$ & - \\
Bile reflux & $1(3.57 \%)$ & $1(3.57 \%)$ & - \\
Anastomosis inflammation & $1(3.57 \%)$ & 0 & - \\
Readmission $(n, \%)$ & $3(10.71 \%)$ & $1(3.57 \%)$ & 0.6110 \\
Reoperation $(n, \%)$ & 0 & 0 & $>0.9999$ \\
Recurrence & 0 & $3(10.71 \%)$ & 0.2364 \\
Decease & 0 & $2(7.14 \%)$ & 0.4909 \\
\hline
\end{tabular}


were 3 readmission cases including 1 anastomosis stricture and 2 abdominal discomfort. In the non-ICG group, there were 1 readmission case due to gastrointestinal bleeding. None of the patients required reoperation during follow-up period. In the non-ICG group, 3 patients suffered from tumor recurrence and 2 of them deceased. In the ICG group, all patients survived in the absence of tumor recurrence.

\section{Discussion}

Herein, we evaluated the safety and efficacy of ICGguided radical laparoscopic gastrectomy in patients with gastric cancer. Compared with routine laparoscopic gastrectomy, our data demonstrated that the ICG-navigated lymphadenectomy could significantly increase the number of lymph node dissections with similar short-term and long-term outcomes. Lymphadenectomy is crucial and challenging for surgeons. According to our study, ICG tracer-guided surgery may assist surgeon to perform safe and effective lymphadenectomy.

Due to the longer excitation wavelength, ICG under NIR imaging exhibits better tissue penetration and better lymph node visualization from hypertrophic adipose tissue compared to other dyes which observed by naked eyes [9]. Thence, the ICG-mediated NIR fluorescent imaging has been applied to identify lymphatic drainage and sentinel lymph nodes during laparoscopic gastrectomy [25-28]. Besides, perigastric lymph node dissection is essential for accurate pathological staging of gastric cancer and subsequent treatment and is associated with the survival of patients [29, 30]. ICG enables real-time observation of lymphatic vessels and lymph nodes, which is helpful for surgeons to perform a more thorough lymphadenectomy and en bloc resection to reduce intraoperative bleeding and vessel damage risk.

The effect of ICG on the number of retrieved lymph nodes is inconsistent according to previous studies. Lan et al. reported no difference in total number of lymph node retrieved from 14 ICG and 65 non-ICG patients [19]. Kwon et al. and Kim et al. found that ICG-guided laparoscopic gastrectomy is capable to retrieve more lymph nodes compared with routine surgery $[18,31]$. A recent randomized study demonstrated that ICG significantly improved the number of lymph node retrieved in D2 lymphadenectomy without increasing the risk of complications [17]. Our study consistently found that ICG could increase the number of lymph nodes retrieved during laparoscopic gastrectomy.

In our experience, the approach of ICG administration is a key factor that affects imaging quality. Traditionally, ICG administration includes subserosal and submucosal injections around the tumor $[16-19,31]$. Previous studies suggested that submucosal injection is superior than subserosal injection in intraoperative lymph node detection [16]. And subserosal injection often caused ICG leakage and surgical field blur [19]. Therefore, we adopted submucosal injection of ICG in our study, Previous studies suggested preoperative injection of ICG $[17,18]$, since they assumed that it takes time for ICG to spread into lymph nodes and prolongs the operation time. Instead, we performed intraoperative injection, and our data showed similar operation time between ICG and non-ICG group. We assume that the visualization of lymph nodes by ICG could accelerate the lymph node dissection. Nevertheless, it remains to be determined the appropriate approach and timing of ICG administration in laparoscopic gastrectomy.

Our study found that ICG is not associated with increased incidence of perioperative complications, which is consistent with previous literature [17-19, 31]. We also found that the postoperative hospital stay was similar between the two groups, which prompted similar recovery process. Our data shows similar incidence of short-term and long-term complications, and no patient suffered from reoperation due to postoperative complications. All above results confirmed the safety of ICGguided laparoscopic gastrectomy.

We are aware of our potential limitations. First, this is a single-center study with limited sample size, which might bring selection bias. We performed PSM to minimize the selection bias and limitations that related to non-randomized and non-blinded property of this study. Further larger multicenter randomized studies are expected to confirm our findings. Second, it requires longer follow-up period to evaluate long-term outcomes, especially relapse-free survival and cumulative survival rates. Third, in the non-ICG group, the laparoscopic radical gastrectomy was performed by PINPOINT system in white light imaging mode or conventional laparoscopic equipment. The types of laparoscopic equipment may bring potential bias to the comparison.

\section{Conclusion}

ICG tracer-guided radical laparoscopic gastrectomy is safe and effective in terms of perioperative, short-term, and long-term outcomes. ICG-navigated lymphadenectomy could increase the number of retrieved lymph node in patients with gastric cancer.

\section{Abbreviations}

ICG: Indocyanine green; PSM: Propensity score matching; LG: Laparoscopic gastrectomy; GC: Gastric cancer; NIR: Near-infrared; ASA: American Society of Anesthesiology

\section{Acknowledgements}

We acknowledge and appreciate all patients enrolled in this study.

\section{Authors' contributions}

$X \mathrm{~L}, \mathrm{SA}$, and $\mathrm{SL}$ contributed to the study design and drafted the manuscript. $X X$ and SA contributed to the study design and data analysis. FS, ZL, and JW contributed to the data collection and extraction. $X \mathrm{~L}, \mathrm{ZY}$, and $\mathrm{XK}$ contributed 
to the follow-up. SA and WG revised the manuscript. All authors have read and approved the final manuscript.

\section{Funding}

This work was supported by grants from the Natural Science Foundation of Jiangsu Province (No. BK20200052).

\section{Availability of data and materials}

The datasets analyzed during the current study are available from the corresponding author on reasonable request.

\section{Declarations}

\section{Ethics approval and consent to participate}

This study was approved by the Ethics Committee of Nanjing Drum Tower Hospital, Medical School of Nanjing University.

\section{Consent for publication}

Not applicable.

\section{Competing interests}

There are no competing interests to declare.

\section{Author details}

${ }^{1}$ Department of General Surgery, Drum Tower Medical College of Nanjing Medical University, 321 Zhongshan Road, Nanjing 210008, Jiangsu, China. 2Department of General Surgery, Drum Tower Hospital, Medical School of Nanjing University, 321 Zhongshan Road, Nanjing 210008, Jiangsu, China. ${ }^{3}$ Department of General Surgery, Beijing Friendship Hospital, Capital Medical University, 95 Yong An Road, Beijing 100050, China.

Received: 17 March 2021 Accepted: 31 August 2021

Published online: 09 September 2021

\section{References}

1. Hu YF, Huang CM, Sun YH, et al. Morbidity and mortality of laparoscopic versus open D2 distal gastrectomy for advanced gastric cancer: a randomized controlled trial. J Clin Oncol. 2016;34:1350-+.

2. $\mathrm{Yu}$ J, Huang $\mathrm{CM}$, Sun $\mathrm{YH}, \mathrm{Su} X, \mathrm{CaO} \mathrm{H}, \mathrm{Hu}$ J, et al. Effect of laparoscopic vs open distal gastrectomy on 3-year disease-free survival in patients with locally advanced gastric cancer: the CLASS-01 randomized clinical trial. JAMA. 2019;321(20):1983-92. https://doi.org/10.1001/jama.2019.5359.

3. Kinoshita T, Uyama I, Terashima M, Noshiro H, Nagai E, Obama K, et al. Long-term outcomes of laparoscopic versus open surgery for clinical stage II/II gastric cancer: a multicenter cohort study in Japan (LOC-A Study). Ann Surg. 2019;269(5):887-94. https://doi.org/10.1097/SLA.0000000000002768.

4. Deng JY, Yamashita $H$, Seto $Y$, Liang $H$. Increasing the number of examined lymph nodes is a prerequisite for improvement in the accurate evaluation of overall survival of node-negative gastric cancer patients. Ann Surg Oncol. 2017;24(3):745-53. https://doi.org/10.1245/s10434-016-5513-8.

5. Biffi R, Botteri E, Cenciarelli S, Luca F, Pozzi S, Valvo M, et al. Impact on survival of the number of lymph nodes removed in patients with nodenegative gastric cancer submitted to extended lymph node dissection. Ejso. 2011;37(4):305-11. https://doi.org/10.1016/j.ejso.2011.01.013.

6. Troyan SL, Kianzad V, Gibbs-Strauss SL, Gioux S, Matsui A, Oketokoun R, et al. The FLARE((TM)) intraoperative near-infrared fluorescence imaging system: a first-in-human clinical trial in breast cancer sentinel lymph node mapping. Ann Surg Oncol. 2009;16(10):2943-52. https://doi.org/10.1245/s1 0434-009-0594-2.

7. Knackstedt R, Couto RA, Ko J, Cakmakoglu C, Wu D, Gastman B. Indocyanine green fluorescence imaging with lymphoscintigraphy for sentinel node biopsy in melanoma: increasing the sentinel lymph nodepositive rate. Ann Surg Oncol. 2019;26(11):3550-60. https://doi.org/1 0.1245/s10434-019-07617-z.

8. Digesu CS, Hachey KJ, Gilmore DM, Khullar OV, Tsukada H, Whang B, et al. Long-term outcomes after near-infrared sentinel lymph node mapping in non-small cell lung cancer. J Thorac Cardiovasc Surg. 2018;155(3):1280-91. https://doi.org/10.1016/j.jtcvs.2017.09.150.

9. Vahrmeijer AL, Hutteman M, van der Vorst JR, van de Velde $\mathrm{CJH}$, Frangioni $J V$. Image-guided cancer surgery using near-infrared fluorescence. Nat Rev Clin Oncol. 2013;10(9):507-18. https://doi.org/10.1038/nrclinonc.2013.123.
10. Ohdaira H, Yoshida M, Okada S, Tsutsui N, Kitajima M, Suzuki Y. New method of indocyanine green fluorescence sentinel node mapping for early gastric cancer. Ann Med Surg. 2017;20:61-5. https://doi.org/10.1016/j.amsu.2 017.06.019.

11. Takeuchi H, Kitagawa Y. Sentinel node navigation surgery in patients with early gastric cancer. Dig Surg. 2013;30(2):104-11. https://doi.org/10.1159/ 000350875.

12. Miyashiro I, Hiratsuka M, Sasako M, et al. High false-negative proportion of intraoperative histological examination as a serious problem for clinical application of sentinel node biopsy for early gastric cancer: final results of the Japan Clinical Oncology Group multicenter trial JCOG0302. Gastric Cancer. 2014;17(2):316-23. https://doi.org/10.1007/s1 0120-013-0285-3.

13. Huh YJ, Lee HJ, Kim TH, Choi YS, Park JH, Son YG, et al. Efficacy of assessing intraoperative bowel perfusion with near-infrared camera in laparoscopic gastric cancer surgery. J Laparoendosc Adv Surg Tech. 2019;29(4):476-83. https://doi.org/10.1089/lap.2018.0263.

14. Kamada T, Yoshida M, Takeuchi H, Narihiro S, Ohdaira H, Suzuki Y. A new method of sentinel node mapping for early gastric cancer using a fluorescent laparoscope that can adjust the intensity of excitation light and quantify the intensity of indocyanine green fluorescence: report of a case. Int J Surg Case Rep. 2020;73:248-52. https://doi.org/10.1016/j. ijscr.2020.07.045.

15. Yamana I, Murakami T, Ryu S, Ichikawa J, Shin Y, Koreeda N, et al. Subtotal gastrectomy for gastric tube cancer using intraoperative indocyanine green fluorescence method. Int J Surg Case Rep. 2020;71:290-3. https://doi.org/1 0.1016/j.jijscr.2020.04.049.

16. Tajima Y, Yamazaki K, Masuda Y, Kato M, Yasuda D, Aoki T, et al. Sentinel node mapping guided by indocyanine green fluorescence imaging in gastric cancer. Ann Surg. 2009;249(1):58-62. https://doi.org/10.1097/SLA Ob013e3181927267.

17. Chen QY, Xie JW, Zhong Q, Wang JB, Lin JX, Lu J, et al. Safety and efficacy of indocyanine green tracer-guided lymph node dissection during laparoscopic radical gastrectomy in patients with gastric cancer: a randomized clinical trial. JAMA Surg. 2020;155(4):300-11. https://doi.org/10.1 001/jamasurg.2019.6033.

18. Kwon IG, Son T, Kim Hl, Hyung WJ. Fluorescent lymphography-guided lymphadenectomy during robotic radical gastrectomy for gastric cancer. JAMA Surg. 2019;154(2):150-8. https://doi.org/10.1001/jamasurg.2018.4267.

19. Lan YT, Huang KH, Chen PH, Liu CA, Lo SS, Wu CW, et al. A pilot study of lymph node mapping with indocyanine green in robotic gastrectomy for gastric cancer. SAGE Open Med. 2017;5:8. https://doi.org/10.1177/205031211 7727444.

20. Ushimaru Y, Omori T, Fujiwara Y, Yanagimoto Y, Sugimura K, Yamamoto K, et al. The feasibility and safety of preoperative fluorescence marking with indocyanine green (ICG) in laparoscopic gastrectomy for gastric cancer. J Gastrointest Surg. 2019;23(3):468-76. https://doi.org/10.1007/s11605-018-3 900-0.

21. Roh CK, Choi S, Seo WJ, Cho M, Son T, Kim HI, et al. Indocyanine green fluorescence lymphography during gastrectomy after initial endoscopic submucosal dissection for early gastric cancer. Br J Surg. 2020;107(6):712-9. https://doi.org/10.1002/bjs.11438.

22. Clavien PA, Barkun J, de Oliveira ML, Vauthey JN, Dindo D, Schulick RD, et al. The Clavien-Dindo classification of surgical complications five-year experience. Ann Surg. 2009;250(2):187-96. https://doi.org/10.1097/SLA.0b013 e3181b13ca2.

23. Japanese Gastric Canc A. Japanese gastric cancer treatment guidelines 2014 (ver. 4). Gastric Cancer. 2017;20(1):1-19. https://doi.org/10.1007/s10120-0160622-4.

24. Japanese Gastric Canc A. Japanese classification of gastric carcinoma: 3rd English edition. Gastric Cancer. 2011;14(2):101-12. https://doi.org/10.1007/s1 0120-011-0041-5.

25. Yano K, Nimura H, Mitsumori N, Takahashi N, Kashiwagi H, Yanaga K. The efficiency of micrometastasis by sentinel node navigation surgery using indocyanine green and infrared ray laparoscopy system for gastric cancer. Gastric Cancer. 2012;15(3):287-91. https://doi.org/10.1007/s10120011-0105-6

26. Tajima Y, Murakami M, Yamazaki K, Masuda Y, Kato M, Sato A, et al. Sentinel node mapping guided by indocyanine green fluorescence imaging during laparoscopic surgery in gastric cancer. Ann Surg Oncol. 2010;17(7):1787-93. https://doi.org/10.1245/s10434-010-0944-0. 
27. Skubleny D, Dang JT, Skulsky S, Switzer N, Tian C, Shi X, et al. Diagnostic evaluation of sentinel lymph node biopsy using indocyanine green and infrared or fluorescent imaging in gastric cancer: a systematic review and meta-analysis. Surg Endosc. 2018;32(6):2620-31. https://doi.org/10.1007/s004 64-018-6100-9

28. Huang L, Wei T, Chen JJ, Zhou DH. Feasibility and diagnostic performance of dual-tracer-guided sentinel lymph node biopsy in cT1-2NOMO gastric cancer: a systematic review and meta-analysis of diagnostic studies. World J Surg Oncol. 2017;15(1):103. https://doi.org/10.1186/s12957-017-1159-7.

29. Smith DD, Schwarz RR, Schwarz RE. Impact of total lymph node count on staging and survival after gastrectomy for gastric cancer: data from a large US-population database. J Clin Oncol. 2005;23(28):7114-24. https://doi.org/1 0.1200/JCO.2005.14.621.

30. Kong SH, Lee HJ, Ahn HS, Kim JW, Kim WH, Lee KU, et al. Stage migration effect on survival in gastric cancer surgery with extended

lymphadenectomy the reappraisal of positive lymph node ratio as a proper N-staging. Ann Surg. 2012;255(1):50-8. https://doi.org/10.1097/SLA.0b013e31 $821 \mathrm{~d} 4 \mathrm{~d} 75$.

31. Kim TH, Kong SH, Park JH, Son YG, Huh YJ, Suh YS, et al. Assessment of the completeness of lymph node dissection using near-infrared imaging with indocyanine green in laparoscopic gastrectomy for gastric cancer. J Gasric Cancer. 2018;18(2):161-71. https://doi.org/10.5230/jgc.2018.18.e19.

\section{Publisher's Note}

Springer Nature remains neutral with regard to jurisdictional claims in published maps and institutional affiliations.

Ready to submit your research? Choose BMC and benefit from:

- fast, convenient online submission

- thorough peer review by experienced researchers in your field

- rapid publication on acceptance

- support for research data, including large and complex data types

- gold Open Access which fosters wider collaboration and increased citations

- maximum visibility for your research: over $100 \mathrm{M}$ website views per year

At BMC, research is always in progress.

Learn more biomedcentral.com/submissions 